\title{
Study of Eccentric and Buckling-Restrained Bracing Systems Used in Frames
}

\author{
Alireza Bahrami \\ Department of Building Engineering, Energy Systems and Sustainability Science, Faculty of Engineering and Sustainable Development, \\ University of Gävle, Gävle, Sweden \\ Email address: \\ Alireza.Bahrami@hig.se

\section{To cite this article:} \\ Alireza Bahrami. Study of Eccentric and Buckling-Restrained Bracing Systems Used in Frames. Journal of Civil, Construction and \\ Environmental Engineering. Vol. 6, No. 4, 2021, pp. 120-125. doi: 10.11648/j.jccee.20210604.13
}

Received: May 16, 2021; Accepted: August 15, 2021; Published: August 31, 2021

\begin{abstract}
The present paper studies eccentric braces (EBs) and buckling-restrained braces (BRBs) used in steel frames. The eccentrically braced frames (EBFs) and buckling-restrained braced frames (BRBFs) that have respectively employed the EBs and BRBs are considered with different types of links as shear, moment-shear and moment links depending on their link length which is an important factor in the design of the EBFs and BRBFs. The BRB consists of a steel core and its surrounding steel tube filled with concrete. The concrete confinement prevents buckling of the steel core. The analysed EBFs and BRBFs by the finite element software ABAQUS under earthquake records are taken into account. Effects of the links of the EBFs and BRBFs on the performance of the frames are discussed. The results uncover that most of the lateral displacements of the EBFs and BRBFs having the shear link are smaller than their counterparts having the moment-shear and moment links, whilst, all the base shear capacities of the former are the greatest. However, majority of the EBFs and BRBFs with the moment link dissipate less energy than their counterparts with the shear and moment-shear links, whereas, most of the link rotations of the former are smaller than the latter. In addition, the BRBFs generally demonstrate better performance than their EBF counterparts.
\end{abstract}

Keywords: Frame, Brace, Steel, Concrete, Eccentric, Buckling

\section{Introduction}

Large lateral displacements can occur in steel moment-resisting frames due to extreme earthquakes. Therefore, limiting the lateral displacements of the frames has specially attracted the attention of researchers in the design of the structures so that potential problems resulting from geometric nonlinearities and brittle or ductile failure of beam-to-column connections can be reduced.

The lateral displacements of frames in structures can be mitigated by the use of the eccentric brace (EB) compared with the moment-resisting frames. Moreover, utilising the buckling-restrained brace (BRB) in the frames can improve their lateral performance compared with the frames using the $\mathrm{EB}$, because the BRB has the advantage of preventing the overall buckling of the core member under the axial compression. The BRB is made up of the steel core member that carries the axial load and the external restraining member which includes the steel tube and concrete infill providing the lateral restraint to the core member.
To date, several investigations have been carried out on the frames employing EBs, i.e., eccentrically braced frames (EBFs), and the frames utilising BRBs, i.e., buckling restrained-braced frames (BRBFs). Roeder and Popov [1] described the system of EBF and its many advantages in the seismic design of structures. Engelhardt and Popov [2] experimentally studied EBF with long links attached to columns. A design procedure for EBF with flexurally dominated links was discussed by Jain et al. [3]. Okazaki et al. [4] conducted tests to examine the performance of links under cyclic loading in EBFs. A parameter as damage distribution capacity factor was defined by Bosco and Rossi [5] for full comprehension of the seismic behaviour of EBFs. A computational investigation was done by Yiğitsoy et al. [6] to assess the stability of EBFs subjected to cyclic loading. Young and Adeli [7] presented results of study on the fundamental periods of EBF structures with varying geometric irregularities. Bosco et al. [8] proposed a design procedure for dual systems with moment resisting frames and EBFs. The seismic response of EBFs under artificial sequences was evaluated by Ruiz-García et al. [9]. Tapia-Hernández and García-Carrera [10] 
discussed results of nonlinear analyses of buildings structured with moment-resisting EBFs. A modified EBF was introduced by Yao et al. [11] to increase the energy dissipation capacity of tension-only concentrically braced beam-through frames. Hollander [12] utilised a tube as a lateral support to prevent buckling of an axially loaded steel rod. Wakabayashi et al. [13] tested BRBs with the application of various de-bonding materials between the brace and the buckling-restraint unit to reduce the friction. BRB was first used practically by Watanabe et al. [14]. Wada et al. [15] presented the design of BRB as a damper in order to dissipate seismic energy. Sabelli et al. [16] studied the seismic response of concentrically braced frames using BRBs. Load bearing capacity of BRBs comprising an $\mathrm{H}$-shaped core element and an external tube was experimentally examined by $\mathrm{Ju}$ et al. [17]. Jiang et al. [18] investigated the contact force between the core and external restraining members to assess the response of BRBs. The seismic performance of reinforced concrete (RC) structures retrofitted with BRBs was experimentally evaluated by Yang et al. [19]. Self-centring dual-steel BRBs were discussed by Jia et al. [20]. Avci-Karatas et al. [21] numerically analysed hysteretic response of BRBs. Pan et al. [22] did the optimal design of steel BRBs against global buckling. However, little work has been attempted to study effects of different kinds of links in the EBFs and BRBFs on their performance under different earthquake records.

This paper compares the EBFs and BRBFs having shear, moment-shear and moment links. ABAQUS was used to perform the nonlinear dynamic analyses of the frames. The obtained results are examined here and the effects of these different kinds of the links on the performance of the frames are discussed.

\section{Numerical Methods}

The ABAQUS software was utilised to do the nonlinear analyses of the frames. The verifications of modelling EBs and BRBs were accomplished [23-27] by the comparison of the modelling results with their corresponding experimental tests results $[28,29]$. It was uncovered that the proposed modelling methods could perfectly predict the performance of the frames. The EBFs and BRBFs were then designed having shear, moment-shear and moment links. The earthquake records of Tabas, Chi-Chi and Northridge were selected for the analyses of the frames, as their characteristics are listed in Table 1. The verified modelling methods were adopted to model and analyse the developed EBFs and BRBFs.

Table 1. Characteristics of earthquake records.

\begin{tabular}{llllll}
\hline Earthquake & Year & $\begin{array}{l}\mathbf{M}_{\mathbf{w}} \\
\text { (Richter Scale) }\end{array}$ & $\begin{array}{l}\text { PGA } \\
(\mathbf{g})\end{array}$ & $\begin{array}{l}\text { PGV } \\
(\mathbf{c m} / \mathbf{s})\end{array}$ & $\begin{array}{l}\text { PGD } \\
(\mathbf{c m})\end{array}$ \\
\hline Tabas & 1978 & 7.40 & 0.928 & 111.35 & 91.10 \\
Chi-Chi & 1999 & 7.70 & 0.89 & 98 & 15.85 \\
Northridge & 1994 & 6.70 & 0.349 & 32.25 & 9.30 \\
\hline
\end{tabular}

\subsection{EBFs with Shear, Moment-Shear and Moment Links}

In the EBFs, the height and width of the frame were 3150 $\mathrm{mm}$ and $3660 \mathrm{~mm}$, respectively. The designs of the shear, moment-shear and moment links were performed for the EBFs. From the designs, the links lengths of $500 \mathrm{~mm}, 750 \mathrm{~mm}$ and $1200 \mathrm{~mm}$ were respectively achieved for the shear, moment-shear and moment links. The columns of the EBFs had pinned ends. Steel with a nominal yield strength of $345 \mathrm{MPa}$ was used for the EBFs. The beam-to-column, brace-to-column and brace-to-beam connections were considered as moment resisting. The shell element S4R was utilised to model the steel members of the frames. The steel material was simulated by the use of a bilinear model. This model had kinematic hardening behaviour to adopt progressive hardening and softening effects. The frames were analysed under the records [23-25]. The modelled and analysed EBFs are illustrated in Figures 1-3.

\subsection{BRBFs with Shear, Moment-Shear and Moment Links}

In the BRBFs, the dimensions of the frames were as the same as those of the EBFs. The lengths of the shear, moment-shear and moment links were also considered similar to those of the EBFs. The same conditions for the ends of the columns and connections between different parts of the BRBFs were taken into account as those of the EBFs. The yield stresses of the steel core and tube were $297.5 \mathrm{MPa}$ and $370 \mathrm{MPa}$, respectively. The compressive strength of concrete at 28 days was $30 \mathrm{MPa}$. The steel material of the BRBFs was modelled like the EBFs. The concrete damage plasticity model was utilised to model the concrete material of the BRBFs. The steel tube was modelled by the shell element S4R. Modelling of the steel core and concrete was done by the solid element C3D8R. The analyses of the frames were conducted under the records [25-27]. Figures 4-6 display the modelled and analysed BRBFs.

\section{Results and Discussions}

Table 2 summarises the designations of the analysed frames. In the labels of the EBFs, the letters after the first three letters respectively represent the type of the link and the earthquake record. Also, in the labels of the BRBFs, the letters after the first four letters respectively designate the type of the link and the earthquake record. The obtained results were presented as diagrams of the lateral displacements, base shears, energy dissipations and rotations [23-27]. Effects of different kinds of the links on the performance of the EBFs and BRBFs are compared and discussed here.

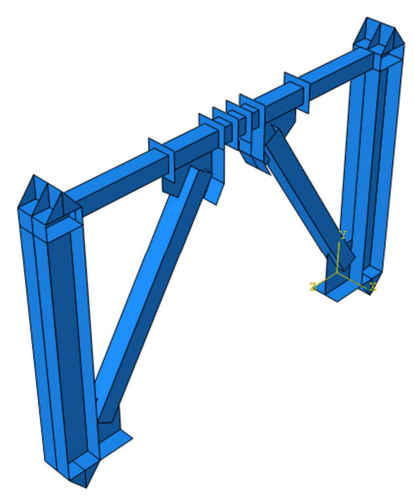

Figure 1. EBF with shear link [23]. 


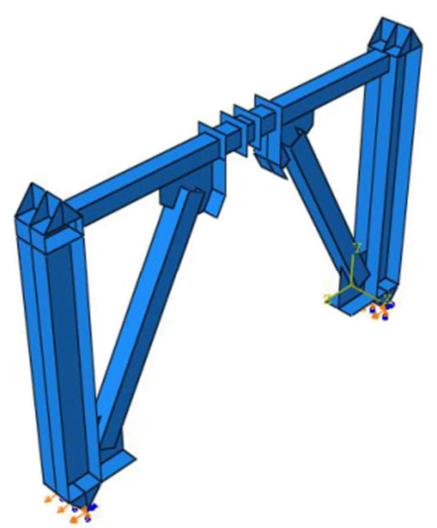

Figure 2. EBF with moment-shear link [24].

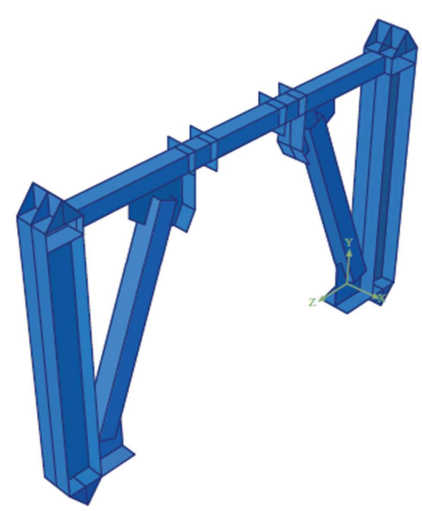

Figure 3. EBF with moment link [25].

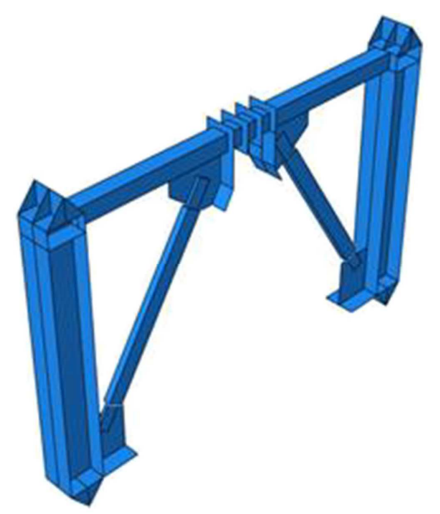

Figure 4. BRBF with shear link [26].

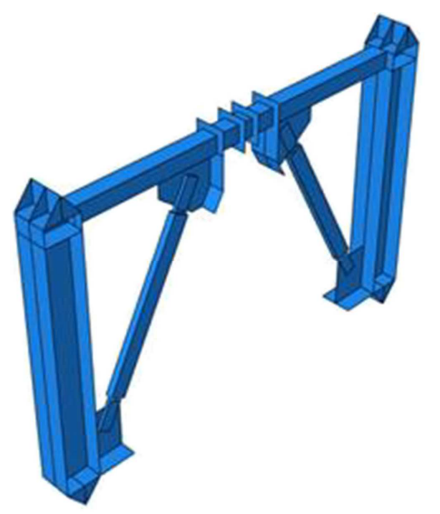

Figure 5. BRBF with moment-shear link [27].

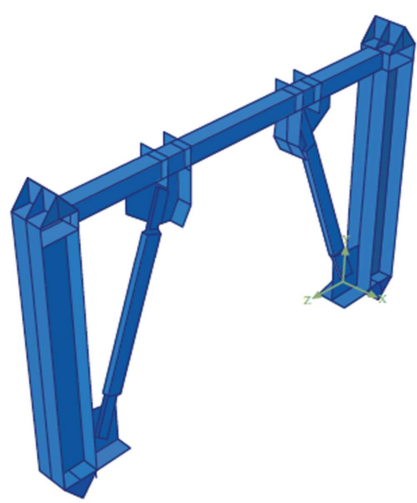

Figure 6. BRBF with moment link [25].

Table 2. Designations of frames.

\begin{tabular}{lllll}
\hline \multirow{2}{*}{ Frame } & \multirow{2}{*}{ Link } & \multicolumn{3}{c}{ Earthquake Record } \\
\cline { 3 - 5 } & & Tabas & Chi-Chi & Northridge \\
\hline \multirow{2}{*}{ EBF } & Shear & EBFST & EBFSC & EBFSN \\
& Moment-Shear & EBFMST & EBFMSC & EBFMSN \\
& Moment & EBFMT & EBFMC & EBFMN \\
& Shear & BRBFST & BRBFSC & BRBFSN \\
BRBF & Moment-Shear & BRBFMST & BRBFMSC & BRBFMSN \\
& Moment & BRBFMT & BRBFMC & BRBFMN \\
\hline
\end{tabular}

\subsection{Lateral Displacements of Frames}

Figures 7-9 indicate the comparisons of the maximum lateral displacements of the analysed frames under the records. It can be seen from Figure 7 that the smallest value of the maximum lateral displacement of the EBFs was related to the EBFST as $3.7 \mathrm{~cm}$ while the smallest value of the maximum lateral displacement of the BRBFs was $1.8 \mathrm{~cm}$ for the BRBFMST which had a slight difference with that of the BRBFST $(1.9 \mathrm{~cm})$. Also, Figure 8 displays that the EBFSC and BRBFSC respectively experienced the smallest value of the maximum lateral displacements of the EBFs and BRBFs as $2.15 \mathrm{~cm}$ and $1.2 \mathrm{~cm}$. The maximum lateral displacements of $1.38 \mathrm{~cm}$ and $1.92 \mathrm{~cm}$ occurred as the smallest ones in the EBFMN and BRBFSN which can be noticed from Figure 9. Therefore, it can generally be stated that most of the frames with the shear link demonstrated smaller lateral displacements than those with the moment-shear and moment links.

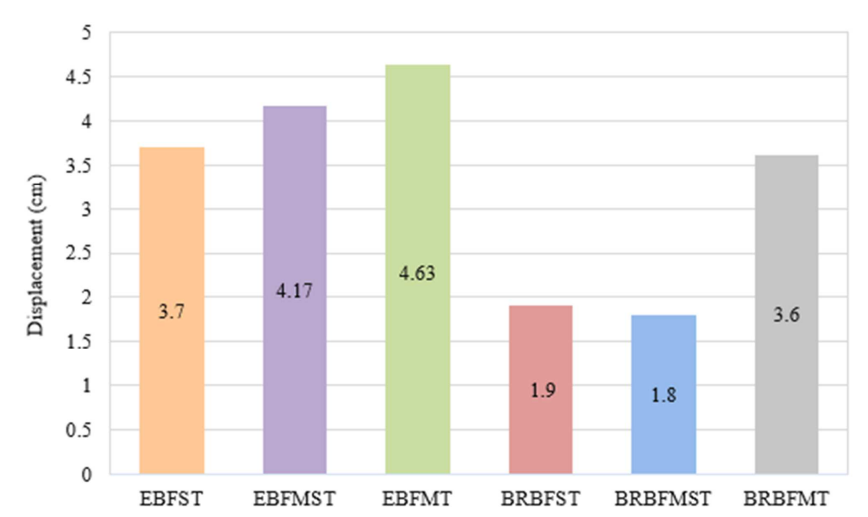

Figure 7. Comparison of maximum lateral displacements of frames subjected to Tabas record. 


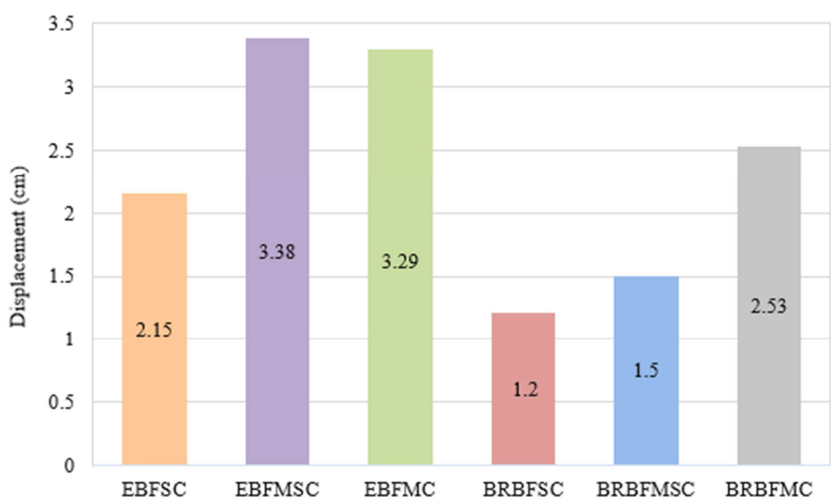

Figure 8. Comparison of maximum lateral displacements of frames subjected to Chi-Chi record.

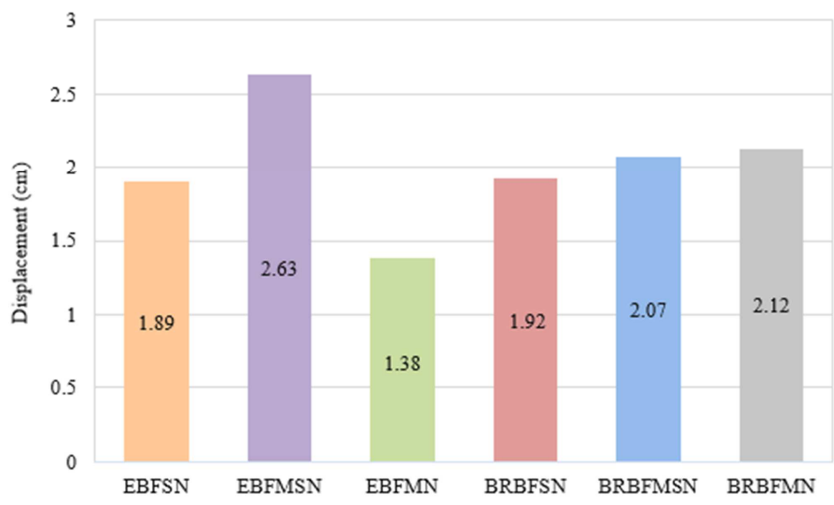

Figure 9. Comparison of maximum lateral displacements of frames subjected to Northridge record.

\subsection{Base Shears of Frames}

The maximum base shears of the frames are shown in Figures 10-12. The figures uncovered that the EBFST, EBFSC and EBFSN respectively provided the greatest values of the maximum base shears as $6950 \mathrm{kN}, 6460 \mathrm{kN}$ and $3660 \mathrm{kN}$ for the EBFs. Moreover, the maximum base shears of the BRBFST (9361 kN), BRBFSC (9203 kN) and BRBFSN $(5298 \mathrm{kN})$ were the highest ones for the BRBFs. Thus, the frames with the shear link had the greatest base shear capacities.

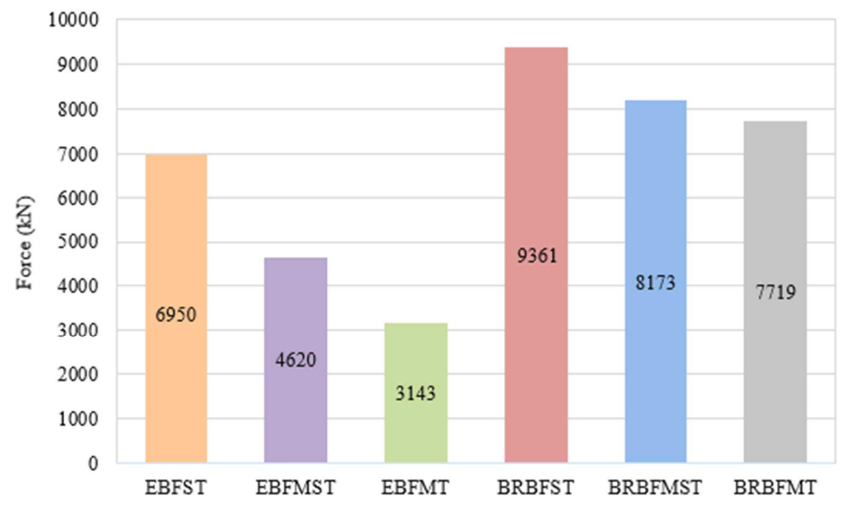

Figure 10. Comparison of maximum base shears of frames subjected to Tabas record.

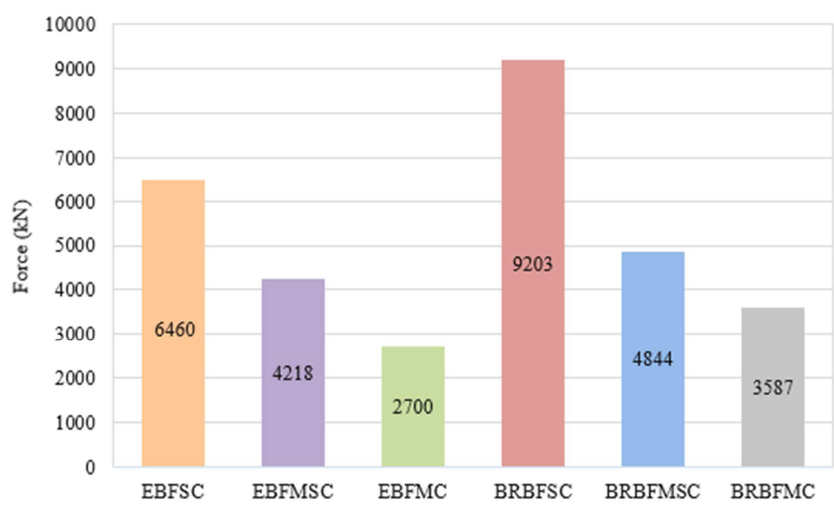

Figure 11. Comparison of maximum base shears of frames subjected to Chi-Chi record.

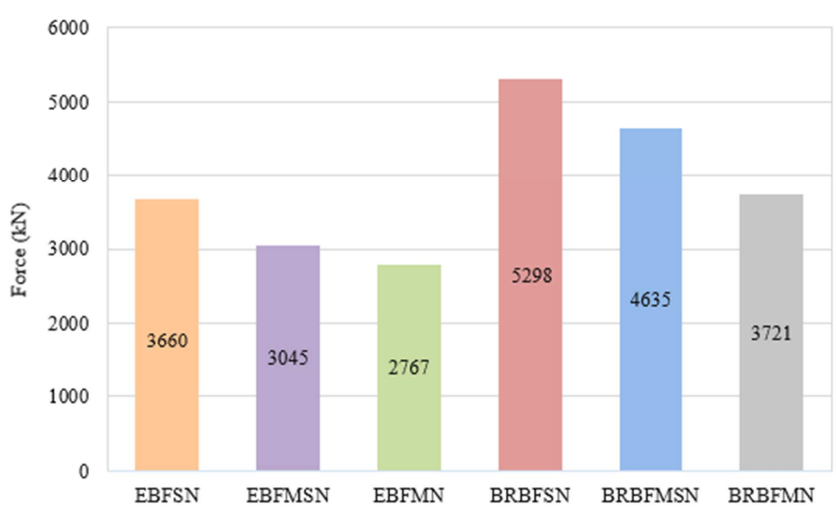

Figure 12. Comparison of maximum base shears of frames subjected to Northridge record.

\subsection{Energy Dissipations of Frames}

Figures 13-15 compare the maximum energy dissipations of the frames. The EBFST, EBFSC and EBFMSN dissipated the maximum energies for the EBFs. However for the BRBFs, the maximum dissipated energies were accomplished by the BRBFST, BRBFMSC and BRBFMSN. As a consequence, many of the frames with the moment link provided less energy dissipations than the ones with the shear and moment-shear links.

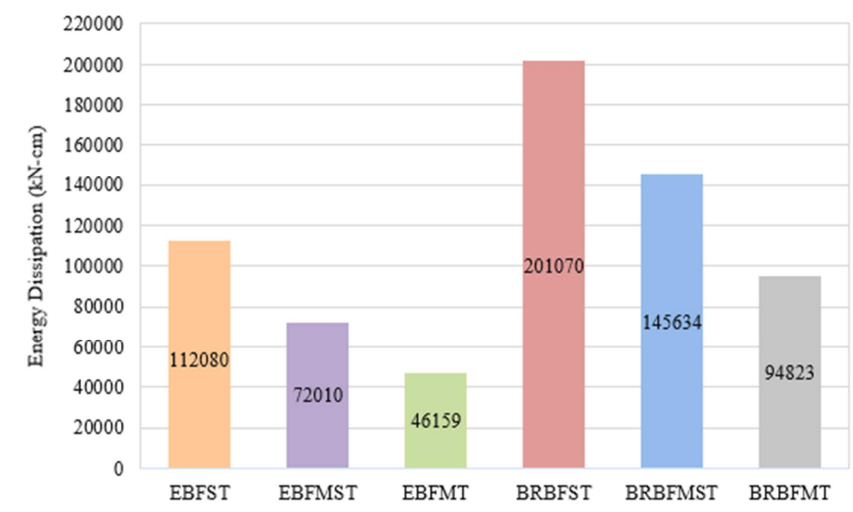

Figure 13. Comparison of maximum energy dissipations of frames subjected to Tabas record. 


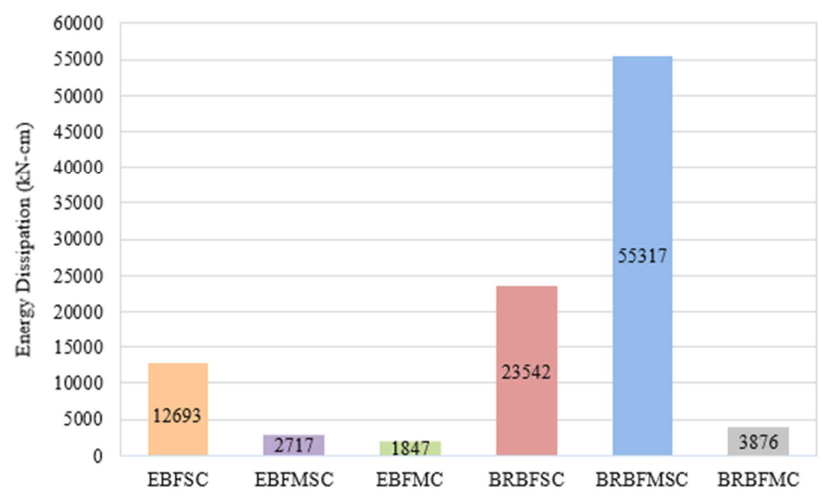

Figure 14. Comparison of maximum energy dissipations of frames subjected to Chi-Chi record.

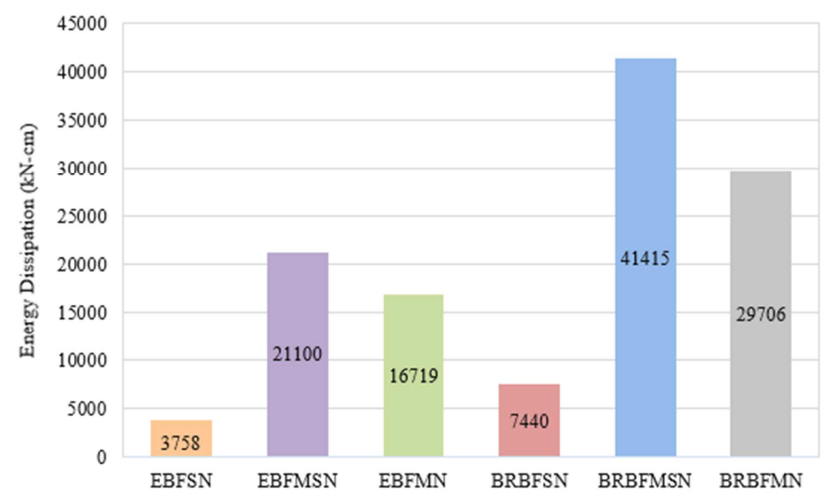

Figure 15. Comparison of maximum energy dissipations of frames subjected to Northridge record.

\subsection{Link Rotations of Frames}

As it can be observed from Figures 16-18, the smallest values of the maximum rotations of the EBFs occurred in the EBFMT, EBFMC and EBFMN as 5.2 rad, 3.7 rad and 1.5 rad, respectively. Nonetheless, the BRBFMST, BRBFMC and BRBFMSN offered the smallest values of the maximum rotations of the BRBFs as $3.9 \mathrm{rad}, 2.8 \mathrm{rad}$ and $4.6 \mathrm{rad}$, respectively. It is worth mentioning that the rotations of the links of the BRBFMST and BRBFMSN were slightly smaller than those of the BRBFMT and BRBFMN, respectively. Considering the afore-mentioned statements, it can be resulted that most of the frames with the moment link rotated less than those with the shear and moment-shear links.

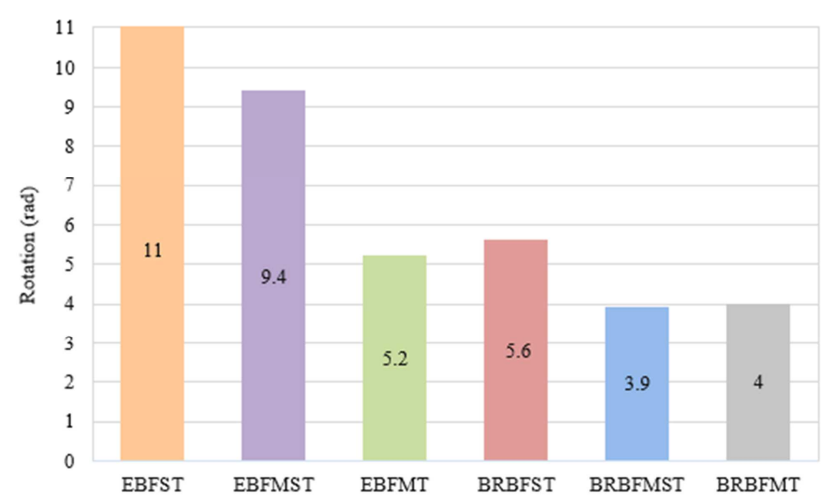

Figure 16. Comparison of maximum link rotations of frames subjected to Tabas record.

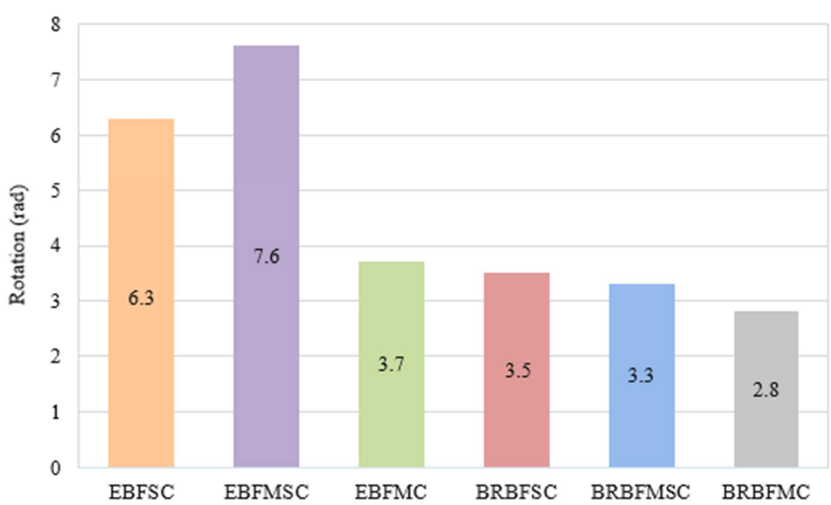

Figure 17. Comparison of maximum link rotations of frames subjected to Chi-Chi record.

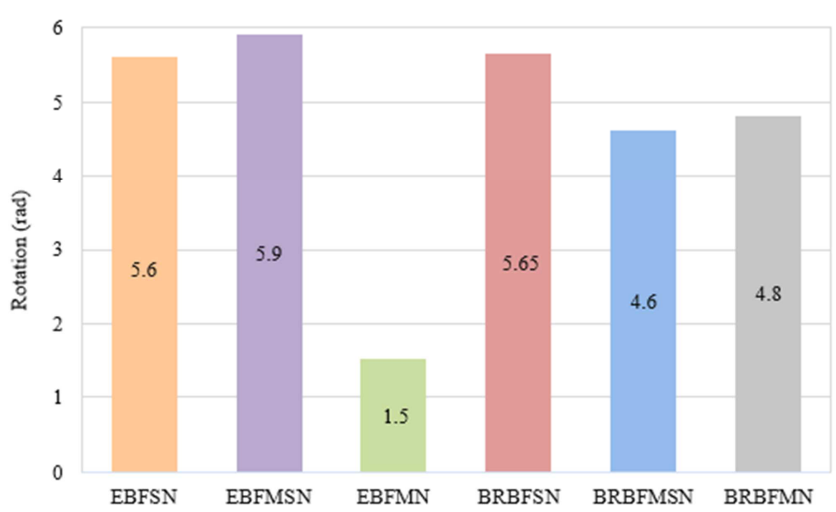

Figure 18. Comparison of maximum link rotations of frames subjected to Northridge record.

\section{Conclusions}

The EBFs and BRBFs having shear, moment-shear and moment links were compared with each other in the current paper. The effects of different types of the links on the performance of the frames were discussed using the results of the analysed frames by ABAQUS under the earthquake records. It was generally concluded that the frames with the shear link were superior to the ones with other links from the lateral displacement viewpoint. Also, the frames with the shear link were the most desirable frames with regard to the base shear capacity. Further, the frames with the shear and moment-shear links were preferred to the ones with the moment link from the energy dissipation point of view. However, the frames with the moment link were usually the most suitable frames with respect to the link rotation.

\section{References}

[1] Roeder, C. W., \& Popov, E. P. (1978). Eccentrically braced steel frames for earthquakes, Journal of the Structural Division, 104 (3), 391-412.

[2] Engelhardt, M. D., \& Popov, E. P. (1992). Experimental performance of long links in eccentrically braced frames, Journal of Structural Engineering, 118 (11), 3067-3088. 
[3] Jain, A., Koboevic, S., \& Redwood, R. (1996). Design and behaviour of eccentrically braced frames with flexural links, Advances in Steel Structures, Proceeding of International Conference on Advances in Steel Structures, Hong Kong, 233-237.

[4] Okazaki, T., Arce, G., Ryu, H-C., \& Engelhardt, M. D. (2005). Experimental study of local buckling, overstrength, and fracture of links in eccentrically braced frames, Journal of Structural Engineering, 131 (10), 1526-1535.

[5] Bosco, M., \& Rossi, P. P. (2009). Seismic behaviour of eccentrically braced frames, Engineering Structures, 31 (3), 664-674.

[6] Yiğitsoy, G., Topkaya, C., \& Okazaki, T. (2014). Stability of beams in steel eccentrically braced frames, Journal of Constructional Steel Research, 96, 14-25.

[7] Young, K. \& Adeli, H. (2016). Fundamental period of irregular eccentrically braced tall steel frame structures, Journal of Constructional Steel Research, 120, 199-205.

[8] Bosco, M., Marino, E. M., \& Rossi, P. P. (2017). A design procedure for dual eccentrically braced-moment resisting frames in the framework of Eurocode 8, Engineering Structures, 130, 198-215.

[9] Ruiz-García, J., Bojorquez, E., \& Corona, E. (2018). Seismic behavior of steel eccentrically braced frames under soft-soil seismic sequences, Soil Dynamics and Earthquake Engineering, 115, 119-128.

[10] Tapia-Hernández, E., \& García-Carrera, S. (2019). Inelastic response of ductile eccentrically braced frames, Journal of Building Engineering, 26, 100903.

[11] Yao, Z., Wang, W., Fang, C., \& Zhang, Z. (2020). An experimental study on eccentrically braced beam-through steel frames with replaceable shear links, Engineering Structures, 206, 110185.

[12] Hollander, M. B. (1966). Prestressed tubes and rods, US Patent No. 3232638.

[13] Wakabayashi, M., Nakamura, T., Kashibara, A., Morizono, T., \& Yokoyama, H. (1973). Experimental study of elasto-plastic properties of precast concrete wall panels with built-in insulating braces, Summaries of Technical Papers of Annual Meeting, Architectural Institute of Japan, Structural Engineering Section, 10, 1041-1044, in Japanese.

[14] Watanabe, A., Hitomi, Y., Saeki, E., Wada, A., \& Fujimoto, M. (1988). Properties of brace encased in buckling-restraining concrete and steel tube, Proceeding of $9^{\text {th }}$ World Conference on Earthquake Engineering, IV, 719-724, Tokyo, Japan.

[15] Wada, A., Connor, J., Kawai, H., Iwata, M., \& Watanabe, A. (1992). Damage tolerant structures, Proceeding of $5^{\text {th }}$ U.S.-Japan Workshop on the Improvement of Structural Design and Construction Practices, Applied Technology Council, ATC-15-4, 27-39, San Diego, CA.

[16] Sabelli, R., Mahin, S., \& Chang, C. (2003). Seismic demands on steel braced frame buildings with buckling-restrained braces, Engineering Structures, 25(5), 655-666.
[17] Ju, Y-K., Kim, M. H., Kim, J., \& Kim, S. D. (2009) Component tests of buckling-restrained braces with unconstrained length, Engineering Structures, 31(2), 507-516.

[18] Jiang, Z., Guo, Y., Zhang, B., \& Zhang, X. (2015). Influence of design parameters of buckling-restrained brace on its performance, Journal of Constructional Steel Research, 105, $139-150$.

[19] Yang, Y., Liu, R., Xue, Y., \& Li, H. (2017). Experimental study on seismic performance of reinforced concrete frames retrofitted with eccentric buckling-restrained braces (BRBs), Earthquakes and Structures-An International Journal, 12 (1), 79-89.

[20] Jia, L-J., Li, R-W., Xiang, P., Zhou, D-Y., \& Dong, Y. (2018). Resilient steel frames installed with self-centering dual-steel buckling-restrained brace, Journal of Constructional Steel Research, 149, 95-104.

[21] Avci-Karatas, C., Celik, O. C., \& Ozmen Eruslu, S. (2019). Modeling of buckling restrained braces (BRBs) using full-scale experimental data, KSCE Journal of Civil Engineering, 23, 4431-4444.

[22] Pan, W. H., Tong, J. Z., Guo, Y. L., \& Wang, C. M., (2020). Optimal design of steel buckling-restrained braces considering stiffness and strength requirements, Engineering Structures, 211, 110437.

[23] Bahrami, A., \& Heidari, M. (2020). Dynamic analysis of steel eccentrically braced frames with shear link, International Journal of Engineering Research and Technology, 13 (2), 233-239.

[24] Bahrami, A., \& Heidari, M. (2020). Dynamic behaviour of steel eccentrically braced frames having moment-shear link, ARPN Journal of Engineering and Applied Sciences, 15 (23), 2793-2799.

[25] Bahrami, A., \& Heidari, M. (2021). Investigation of steel frames equipped with steel eccentric braces and steel-concrete buckling-restrained braces having moment link, Open Construction and Building Technology Journal, 15, 55-69.

[26] Bahrami, A., \& Heidari, M. (2020). Evaluation of structural response of composite steel-concrete eccentrically buckling-restrained braced frames, Journal of Applied Engineering Science, 18 (4), 591-600.

[27] Bahrami, A., \& Heidari, M. (2021). Effectiveness of composite steel-concrete buckling-restrained braces (BRBs) for steel frames, International Journal of Advanced Research in Engineering and Technology, 12 (3), 42-55.

[28] Berman, J. W., \& Bruneau, M. (2007). Experimental and analytical investigation of tubular links for eccentrically braced frames, Engineering Structures, 29, 1929-1938.

[29] Mirtaheri, M., Gheidi, A., Zandi, A. P., Alanjari, P., \& Rahmani Samani, H. (2011). Experimental optimization studies on steel core lengths in buckling restrained braces, Journal of Constructional Steel Research, 67, 1244-1253. 